\title{
Effects of Monensin and Tunicamycin on Cell Surface Expression of Carcinoembrionic Antigen in a Human Gastric Cancer Cell Line
}

\author{
Tatsuo Kodama*, Takayuki Harada**, Makoto Nagasaki**, Tomoichi Setogawa* \\ and Shigeru Morikawa** \\ ${ }^{*}$ Department of Ophthalmology and ${ }^{* *}$ Department of Pathology, Shimane Medical University, Izumo 693
}

Received for publication August 23, 1995 and in revised form December 4, 1995

\begin{abstract}
Carcinoembrionic antigen (CEA) is a glycosyl-phosphatidylinositol (GPI) anchored protein which has $\mathbf{N}$-glycosylation sites. To determine whether it acts as a cell surface adhesion molecule or functions as molecular transportation, we studied the stability and regulation of CEA expression in a human gastric cancer cell line (HPE-GAC-T) using immunological techniques. Amounts of CEA in the cytoplasm of GAC-T cells were increased by stimulation with 12-O-tetradecanoylphorbol-13-acetate (TPA), with or without calcium ionophore A23187. Synergistic effects of TPA with A23187 (TPA/A23187) on the cell surface expression of CEA were observed dose- and timedependently. Tunicamycin, an inhibitor of
\end{abstract}

$\mathrm{N}$-linked glycosylation, decreased the total cellular CEA level of mature form of $170 \mathrm{kD}$. Monensin, an inhibitor of intracellular transport, also decreased the amount of high molecular weight $(170,000)$ CEA, but the smaller molecular weight $(140,000)$ CEA that appeared by TPA/ A23187 treatment remained unaffected. Both drugs suppressed GAC-T cell growth moderately at high doses used, but did not suppress the increased cell surface expression of CEA induced with TPA/A23187. Up-regulation and stability of the membrane expression of CEA may involve the physiological role CEA plays on the cell surface.

Key Words Carcinoembrionic antigen, Phorbol ester, Calcium ionophore, Tunicamycin, Monensin

\section{Introduction}

CEA is one of the best established tumor markers associated with adenocarcinomas of the gastrointestinal tract and other organs [7]. The cancer specificity of CEA is, however, controversial, because several CEA-related antigens are present in normal tissues and fluids [12, 21]. Recently, the primary structure of CEA peptide was defined by cDNA cloning, proving that the peptide is composed of five domains [19]. The $\mathrm{COOH}$-terminal domain was demonstrated as the membrane-anchoring domain, where a glycosyl-phosphatidylinositol (GPI) moiety anchors CEA to the cell membrane [24]. As many as 28 possible $\mathrm{N}$-glycosylation sites are found in the peptide region [19].

However, the function of CEA is not yet clear. CEA can affect the homotypic sorting of cells in a heterogeneous population of aggregating cells by functioning as a

Correspondence to: Tatsuo Kodama, MD, Department of Ophthalmology, Shimane Medical University, 89-1 Enya-cho, Izumo 693, Japan. homotypic intercellular adhesion molecule [3]. Normal colon mucosa produces and releases CEA quite actively in vitro, as cancerous tissues do, where the perturbation of localized CEA is observed [12]. To investigate what physiological role CEA plays, whether it acts as a cell surface adhesion molecule or functions as molecular transportation, we looked at the stability of the cell surface expression of CEA in a human gastric cancer cell line, HPEGAC-T cells. The GAC-T cells were stimulated to induce CEA production with a phorbol ester, TPA and/or a calcium ionophore, A23187. Effects of monensin, an ionophore that blocks protein transport at the trans-Golgi side $[9,27]$, and tunicamycin, an inhibitor of $\mathrm{N}$-glycosylation enzyme $[25,29]$, on CEA production and cell surface expression in GAC-T cells were examined.

\section{Materials and Methods \\ Cell line}

The human gastric cancer cell line, HPE-GAC-T, was established in our laboratory [10]. Cells were maintained 
in a single-cell suspension culture in RPMI 1640 (Nissui Pharmaceutical Co. Ltd., Tokyo, Japan) and supplemented with $10 \%$ fetal calf serum (FCS) (KC Biologicals, Lenexa, USA) at $37^{\circ} \mathrm{C}$ in $5 \% \mathrm{CO}_{2}$ and $95 \%$ air.

\section{Antibodies}

Rabbit anti-human CEA antibodies (DAKO, Copenhagen, Denmark), which react with the peptide region of CEA molecules, were rendered free of antinonspecific cross-reacting antigen antibodies by absorption with human spleen tissue acetone powder. FITC-labelled goat anti-rabbit immunoglobulins $(\mathrm{IgG}+\mathrm{M}+\mathrm{A})$ were obtained from Cappel (Westchester, PA, USA). Affinity purified goat anti-rabbit IgG conjugated with horseradish peroxidase was purchased from Bio-Rad Laboratories (Richmond, CA, USA).

\section{Chemicals}

Monensin was obtained through the courtesy of Eli Lilly Japan Co., Ltd. Phorbol ester TPA, calcium ionophore A23187, and glycosylation inhibitor tunicamycin were obtained from Sigma (St. Louis, MO, USA). All other chemicals were of analytical grade.

\section{Treatment with reagents}

TPA, tunicamycin, and monensin were dissolved with dimethyl sulfoxide (DMSO) at concentrations of $1 \mathrm{mg} / \mathrm{ml}$, $10 \mathrm{mg} / \mathrm{ml}$, and $10 \mathrm{mM}$, respectively. A23187 was dissolved at a concentration of $1 \mathrm{mg} / \mathrm{ml}$ in the culture medium and DMSO. GAC-T cells, $1 \times 10^{5} / \mathrm{ml}$, were cultured at $37^{\circ} \mathrm{C}$ in $5 \mathrm{ml}$ of the medium with reagent at various concentrations for indicated periods of time.

\section{Immunofluorescence}

Incubated cells were washed with Eagle's minimal essential medium (MEM) (Nissui Pharmaceutical Co), smeared on glass slides, and fixed with acetone for 10 min. After washing with phosphate buffered saline (PBS) (pH 7.3), slides were blocked with normal goat serum (diluted $1: 20$ in PBS) for $30 \mathrm{~min}$ and drained off. Then the sections were incubated with rabbit anti-human CEA antibodies (diluted 1:20 in PBS) in a moist chamber at room temperature for $1 \mathrm{hr}$. Following washing with PBS three times, the smears were incubated with FITClabelled goat anti-rabbit immunoglobulins (diluted $1: 20$ in PBS) for $1 \mathrm{hr}$. These smear slides were then washed with PBS and examined under a Carl Zeiss fluorescence microscope.

\section{Flow cytometric analysis}

Incubated cells were washed twice with cold PBS containing 5\% FCS and $0.1 \%$ sodium azide. Aliquots $(2 \times$ $10^{5}$ cells $/ 10 \mu \mathrm{l}$ ) were incubated in a 96 -well microtiter plate with $25 \mu$ l of rabbit anti-human CEA antibodies (diluted $1: 20$ in PBS) or normal rabbit serum (as a background control) on ice for $30 \mathrm{~min}$. After washing three times, the cells were stained with $25 \mu \mathrm{l}$ of FITC-labelled goat anti-rabbit immunoglobulins (diluted $1: 20$ in PBS) for $30 \mathrm{~min}$ on ice. Finally, $25 \mu \mathrm{l}$ of PBS diluted $10 \mu \mathrm{g} / \mathrm{ml}$ propidium iodide (PI) (Sigma) was added to stain the dead cells. The aliquots were again washed three times, resuspended in $200 \mu \mathrm{l}$ of MEM, filtered through nylon mesh (300 mesh/inch width), and subjected to flow cytometry. Flow cytometric studies were performed with FACSter (Becton Dickinson FACS System, USA). At least 9,900 viable cells were counted for each determination.

\section{Western blot analysis}

Incubated cells were washed twice with MEM and $5 \times$ $10^{6}$ cells were lysed with $1 \mathrm{ml}$ of the extract buffer $(0.5 \%$ Nonidet P-40 in $0.02 \mathrm{M}$ Tris, $0.3 \mathrm{mM} \mathrm{NaCl}, 1 \mathrm{mM} \mathrm{MgCl}$, 2 mM EDTA, 10\% glycerol, $2 \mathrm{mM}$ phenylmethyl sulfonyl fluoride, $\mathrm{pH} \mathrm{9.0)} \mathrm{for} 2 \mathrm{hr}$ on ice. Insoluble materials were removed by centrifugation for $20 \mathrm{~min}$ at $15,000 \mathrm{rpm}$. After dialysis with PBS, protein concentrations of cell lysates were measured by Lowry's method [13]. Each lysate was diluted $2: 1$ in SDS, and boiled at $100^{\circ} \mathrm{C}$ for $90 \mathrm{sec}$. These lysates were subjected to SDS-PAGE using $7.5 \%$ separating gel, and electrophoretically transferred to a nitrocellulose membrane (Bio-Rad Laboratories). The membrane was blocked by incubation for $30 \mathrm{~min}$ at room temperature in $20 \mathrm{mM}$ Tris, $500 \mathrm{mM} \mathrm{NaCl}$ (pH 7.5) containing $5 \%$ skim milk. The membrane was incubated with rabbit anti-human CEA antibodies (diluted $1: 2,000$ in Tris-buffered saline (TBS)- $0.5 \%$ skim milk) overnight in the cold. After washing with TBS and $0.05 \%$ Tween 20-TBS, the membrane was further incubated with horseradish peroxidase conjugated goat anti-rabbit immunoglobulins (diluted $1: 2,000$ in TBS-0.5\% skim milk) for $2 \mathrm{hr}$ at room temperature, washed again, and developed with $0.02 \%$ 3,3-diaminobenzidine tetrahydrochloride as substrate.

\section{Results}

Immunofluorescence of $C E A$ in $G A C-T$ cells stimulated by a combination of TPA with A23187 (TPA/A23187)

To examine the effect of TPA and A23187 on the location and amount of CEA in GAC-T cells, we performed indirect immunofluorescence (Fig. 1). In untreated GAC-T cells, weak but distinct cell surface fluorescence and fine granular cytoplasmic fluorescence were observed in a limited number of cells $(2.4 \%$ fluorescent positive cells, counted at least 800 cells in each slide under a fluorescent microscope, objected $\times 40$ ) (Fig. 1a). Treatment with A23187 alone had no effect on CEA expression or on positive cell population (2.4\%) (Fig. 1b). Conversely, TPA treatment resulted in both enhanced expression of CEA, especially in the cytoplasm, and an increased population of GAC-T cells $(6.3 \%, p<0.05$ to untreated culture) (Fig. 1c). Enhanced immunofluorescence in cytoplasm and cell surface were also observed in GAC-T cells when they were treated with TPA/A23187 (Fig. 1d). No synergistic effect of TPA and A23187 on positive cell 

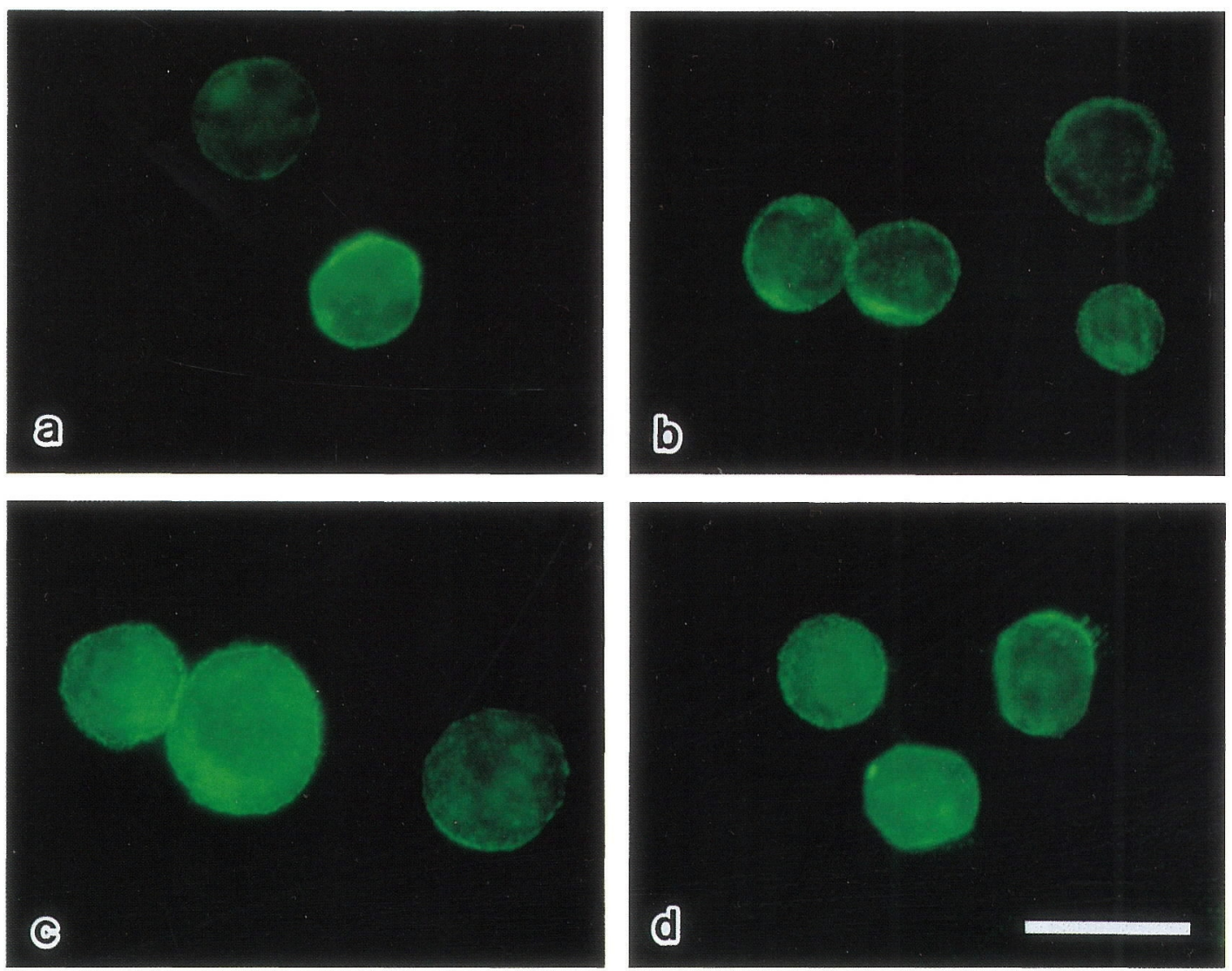

Fig. 1. The effects of A23187 and TPA on immunofluorescence localization of CEA in GAC-T cells. The cells were treated with $0.1 \%$ DMSO alone (a), $0.5 \mu \mathrm{g} / \mathrm{ml} \mathrm{A23187} \mathrm{(b),} 2.5 \mathrm{ng} / \mathrm{ml} \mathrm{TPA} \mathrm{(c),} \mathrm{and} \mathrm{A23187} \mathrm{(0.5} \mu \mathrm{g} / \mathrm{ml}) / \mathrm{TPA}(2.5 \mathrm{ng} / \mathrm{ml})$ (d) for three days. Indirect immunofluorescence was performed as described in Materials and Methods. Bar $=10 \mu \mathrm{m}$.

population was observed $(5.9 \%)$.

\section{Western blot analysis of CEA in GAC-T cells induced by TPA/A23187}

To estimate the increased amount of CEA stimulated by TPA/A23187 semiquantitatively, we performed Western blot analysis on total cell lysates from various cultures. Untreated and A23187-treated cells showed a relatively broad single band with the approximate molecular weights of 180,000 and 170,000 , respectively (Fig. 2A-lane a, b). A23187 treatment shifted the molecular size of CEA in GAC-T cells to a lower one, although the density of the CEA band was unchanged. A 180,000-band with increased density was observed in TPAstimulated GAC-T cells (Fig. 2A-lane c). TPA/A23187 treatment produced a different pattern that consisted of a relatively broad band of 170,000 and a sharp band of approximately 140,000 (Fig. 2A-lane d). We also examined the CEA levels in the culture medium from the same samples of GAC-T cells stimulated with TPA (Fig. 2B). A dense band at 180,000 was detected in stimulated cell lysate (Fig. 2B-lane a) and the culture medium (Fig. 2B-lane c). No immunoblot was detected in the culture medium of untreated cells. These results suggest that TPA induced CEA production and release in GAC-T cells.

\section{Flow cytometric analysis on cell surface expression of CEA in GAC-T cells stimulated by TPA/A23187}

Flow cytometry was performed to estimate whether increased production of CEA resulted in an increased cell surface expression of CEA. Fig. 3 shows clearly the synergistic effect on cell surface expression of CEA between TPA and A23187. Increasing cell surface expression of CEA in GAC-T cells stimulated by TPA/A23187 was a dose-dependent phenomenon, and both stimulants were required to elicit full CEA expression (Fig. 4). Kinetic study on cell surface expression of CEA induced in GAC-T cells after stimulation by TPA/A23187 was done with flow cytometry (Fig. 5). Twelve hours after incubation with TPA/A23187, mean fluorescence intensity of GAC-T cells increased to $150 \%$ of that of untreated cells, and bright fluorescent cell populations appeared. Thereafter, bright cell populations increased in number, and two peaks were observed in the histogram after $72 \mathrm{hr}$ ( $740 \%$ increase in mean fluorescence intensity). 


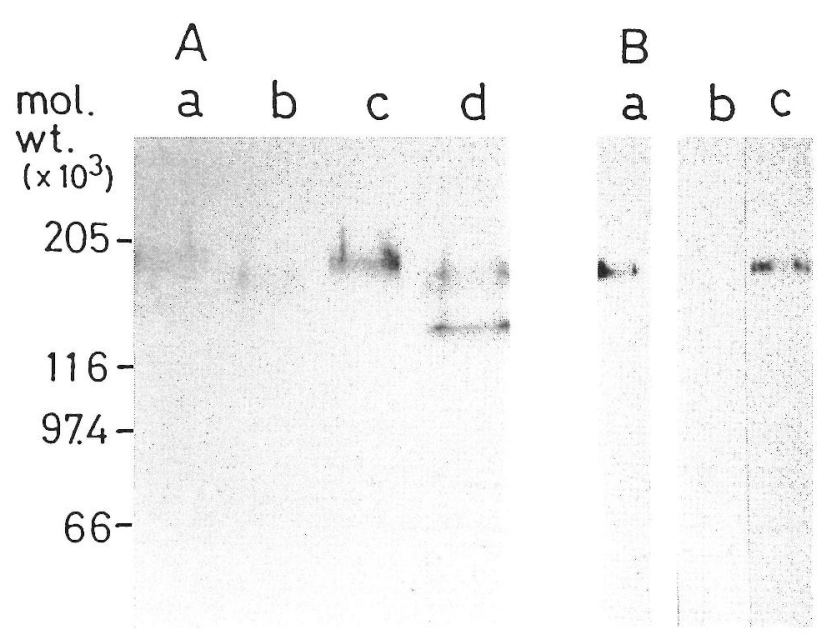

Fig. 2. The effects of A23187 and TPA on total cellular CEA in GAC-T cells (A). The cells were incubated with 0.1\% DMSO alone (lane A-a), $0.5 \mu \mathrm{g} / \mathrm{ml} \mathrm{A23187} \mathrm{(lane} \mathrm{A-b),} 2.5 \mathrm{ng} / \mathrm{ml}$ TPA (lane A-c), and A23187 $(0.5 \mu \mathrm{g} / \mathrm{ml}) / \operatorname{TPA}(2.5 \mathrm{ng} / \mathrm{ml})$ (lane A-d) for three days. Each sample concentration was equalized by Lowry's method. The amounts of proteins loaded on the gels were $20 \mu \mathrm{g}$ (lane A). CEA levels in culture medium and cell lysate of GAC-T cells stimulated with TPA (B). The cells were treated with TPA $(2.5 \mathrm{ng} / \mathrm{ml})$ for three days and lysed in extract buffer (lane B-a). Culture medium of untreated cells (incubated with $0.1 \%$ DMSO alone, lane B-b) and TPA $(2.5 \mathrm{ng} / \mathrm{ml})$ treated cells (lane B-c) were condensed into a 40-fold concentration. Lysates and culture medium were subjected to Western blot analysis, as described in Materials and Methods.

\section{Effects of tunicamycin and monensin on CEA production} and expression of GAC-T cells stimulated by TPA/ A23187

To determine whether the amouni of CEA production is affected by its processing inhibitors, we performed

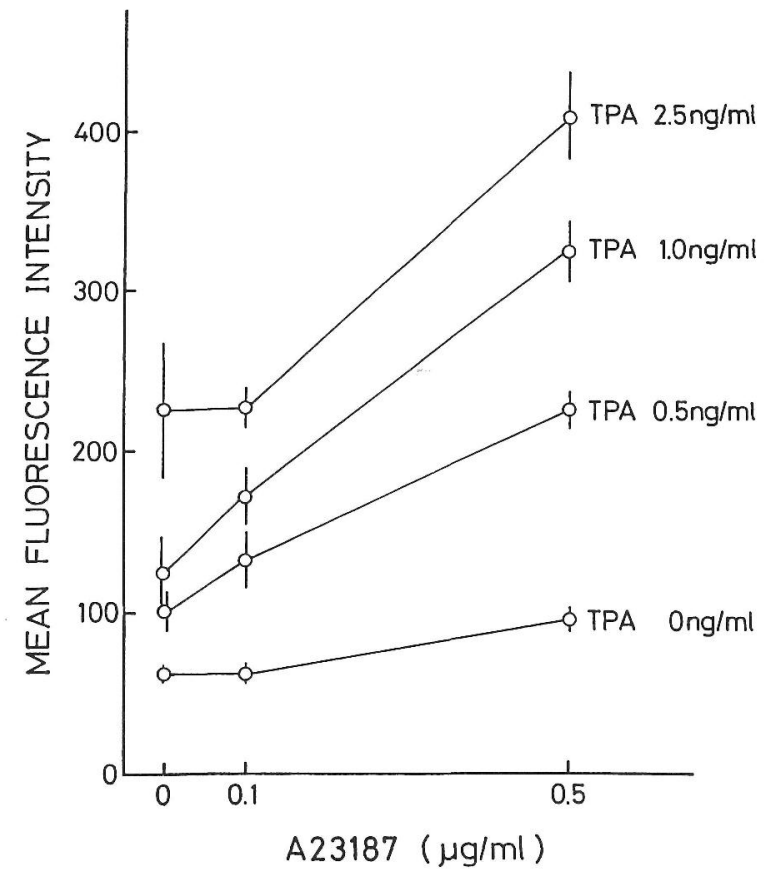

Fig. 4. The effects of A23187 and TPA dosage on cell surface expression of CEA in GAC-T cells. The cells were incubated in triplicate with the combination of A23187 $(0,0.1$, and $0.5 \mu \mathrm{g} / \mathrm{ml})$ and TPA $(0,0.5,1.0$, and $2.5 \mathrm{ng} / \mathrm{ml})$ for three days. Flow cytometric analysis was done, as described in Materials and Methods. The data obtained were expressed as mean fluorescence intensity (MFI) and were linearized after subtraction of background MFI.

Western blot analysis on tunicamycin- or monensintreated GAC-T cells stimulated with and without TPA/A23187. Treatment with tunicamycin $(1 \mu \mathrm{g} / \mathrm{ml}$, 3 days) produced a density of the broad band of 180,000 which diminished markedly in nonstimulated GAC-T cells

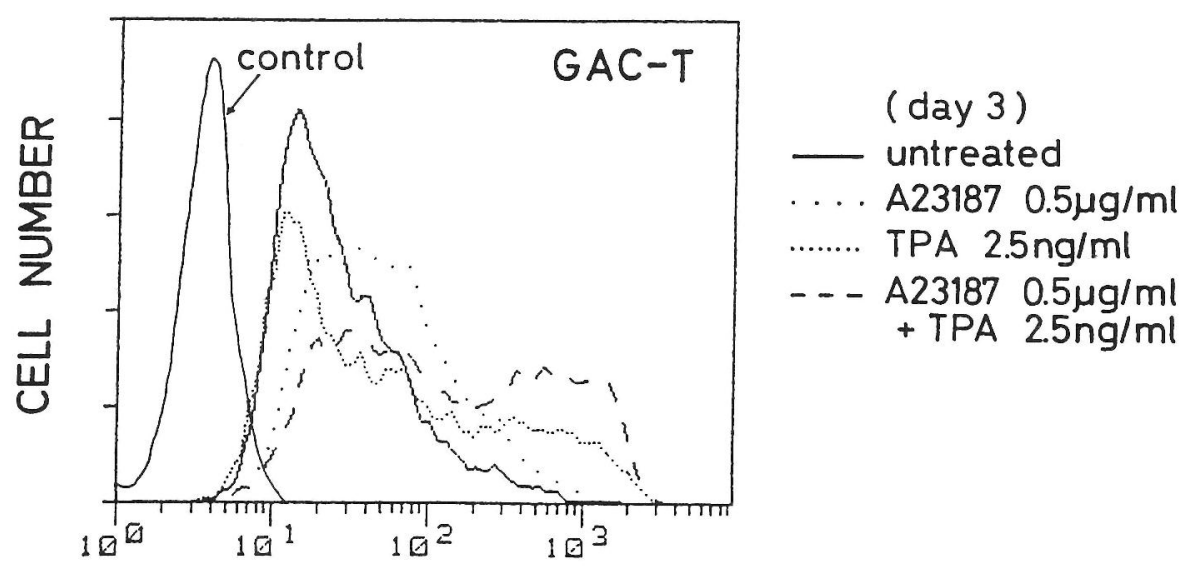

\section{FLUORESCENCE INTENSITY}

Fig. 3. The effects of A23187 and TPA on cell surface expression of CEA in GAC-T cells. The cells were cultured with the reagents at indicated concentrations for three days and subjected to flow cytometry, as described in Materials and Methods. 


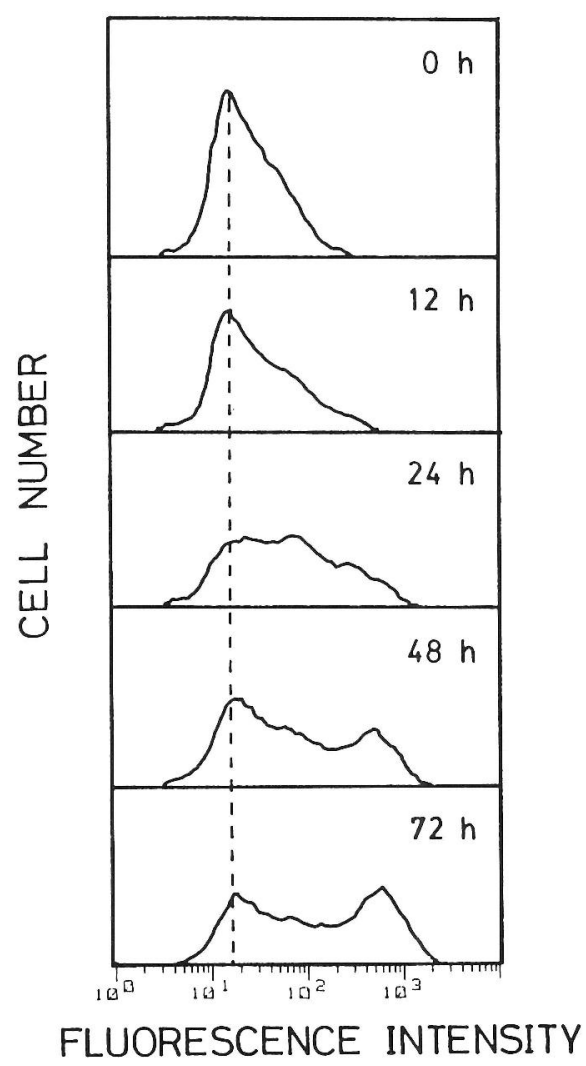

Fig. 5. Time kinetics of induction of cell surface expression of CEA in GAC-T cells by A23187/TPA. The cells were incubated with A23187 $(0.5 \mu \mathrm{g} / \mathrm{ml})$ and TPA $(2.5 \mathrm{ng} / \mathrm{ml})$ for various periods of time, as indicated. Flow cytometric analysis was done as described in Materials and Methods.

(Fig. 6A-lane b). On the other hand, monensin treatment $(1 \mu \mathrm{M})$ resulted in a split of the broad band of 180,000 and caused the appearance of two additional small bands in the immunoblot of nonstimulated GAC-T cells, without apparent reduction of staining density (Fig. 6A-lane c). GAC-T cells stimulated by TPA/A23187 produced two intense bands for CEA, 170,000 and 140,000 (Fig. 6Blane b). The addition of tunicamycin $(1 \mu \mathrm{g} / \mathrm{ml})$ in the culture reduced the density of the band of 170,000 and eliminated the smaller band of 140,000 (Fig. 6B-lane c). The addition of monensin $(1 \mu \mathrm{M})$ in the culture also reduced the density of the 170,000 band, but the 140,000 band seemed to remain unaffected (Fig. 6B-lane d).

To evaluate cell membrane expression of CEA, which has $\mathrm{N}$-glycosylation sites in the peptide region, we performed flow cytometric analysis on tunicamycin- or monensintreated GAC-T cells stimulated with and without TPA/ A23187. Flow cytometric analysis revealed that neither tunicamycin nor monensin added in the cultures at various doses for three days suppressed the cell surface CEA expression of unstimulated GAC-T cells (Fig. 7A, B). Conversely, enhanced membrane expression of CEA in GAC-T cells incubated with higher doses of tunicamycin

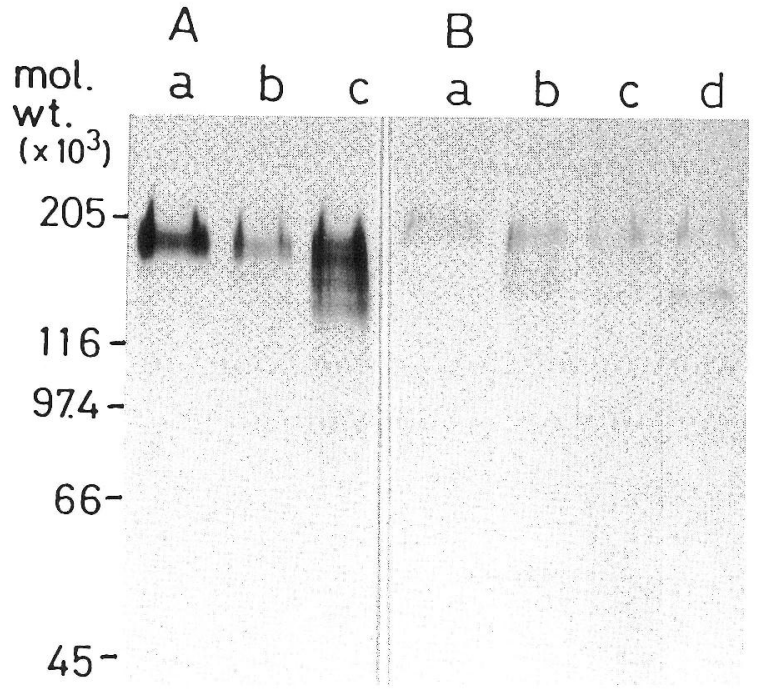

Fig. 6. The effects of tunicamycin and monensin on total cellular CEA in GAC-T cells (A). The cells were incubated with $0.1 \%$ DMSO alone (lane $\mathbf{A}-\mathrm{a}$ ), $1 \mu \mathrm{g} / \mathrm{ml}$ tunicamycin (lane $\mathbf{A}-\mathrm{b}$ ), and $1 \mu \mathrm{M}$ monensin (lane $\mathbf{A}-\mathrm{c}$ ) for three days. The effects of tunicamycin and monensin on total cellular CEA induced by A23187/TPA in GAC-T cells (B). The cells were incubated with $0.1 \%$ DMSO alone (lane B-a), A23187 $(0.5 \mu \mathrm{g} / \mathrm{ml}) / \mathrm{TPA}(2.5 \mathrm{ng} / \mathrm{ml})$ (lane B-b), A23187 $(0.5 \mu \mathrm{g} / \mathrm{ml}) /$ TPA $(2.5 \mathrm{ng} / \mathrm{ml})+1 \mu \mathrm{g} / \mathrm{ml}$ tunicamycin (lane B-c), and A23187 $(0.5 \mu \mathrm{g} / \mathrm{ml}) / \mathrm{TPA}(2.5 \mathrm{ng} / \mathrm{ml})+1 \mu \mathrm{M}$ monensin (lane B-d) for three days. Each sample concentration was equalized by Lowry's method. The amounts of proteins loaded on the gels were $40 \mu \mathrm{g}$ (lane A) and $15 \mu \mathrm{g}$ (lane B). Lysates were subjected to Western blot analysis, as described in Materials and Methods.

(100 ng/ml-1 $\mu \mathrm{g} / \mathrm{ml})$ and monensin (100 nM-1 $\mu \mathrm{M})$ showed a shift in peaks by histograms to higher fluorescence intensity. Cell viabilities of GAC-T cells, incubated with tunicamycin and monensin at the doses used in this study for three days, were not affected (data not shown). Effects of tunicamycin and monensin on CEA membrane expression of GAC-T cells stimulated by TPA/A23187 were examined with flow cytometry. As shown in Fig. 8 , both tunicamycin $(1 \mu \mathrm{g} / \mathrm{ml})$ and monensin $(1 \mu \mathrm{M})$ treatment for three days did not affect the cell surface expression of CEA on the TPA/A23187-stimulated GAC-T cells.

Taken together, these results suggest that the amount of CEA expressed on the cell membrane of GAC-T cells did not correlate with the amount of whole cellular CEA, especially with the mature form CEA.

\section{Discussion}

As CEA is a membrane-associated-GPI-anchored glycoprotein, the assay of CEA generally has been performed by radioimmunoassay or enzyme-linked immunosorbent assay on the extracts of cell lysate or on culture 


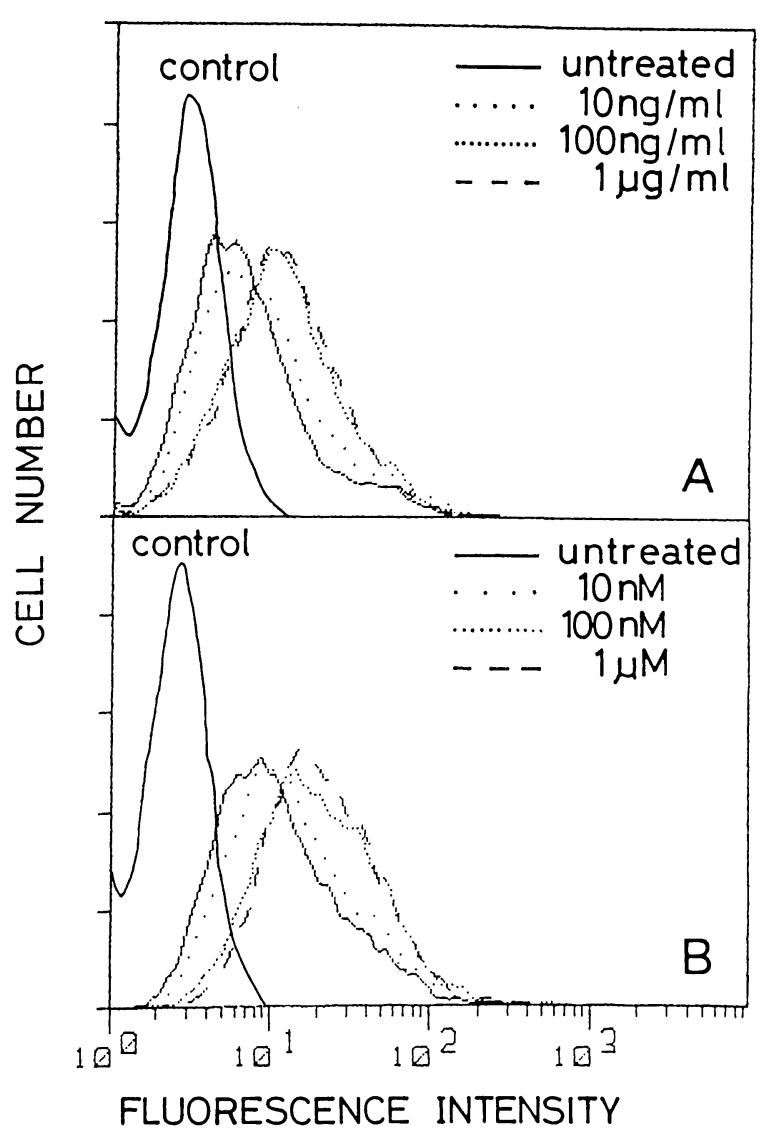

Fig. 7. The effects of tunicamycin (A) and monensin (B) on cell surface expression of CEA in GAC-T cells. The cells were cultured with the reagents at indicated concentrations for three days and subjected to flow cytometry, as described in Materials and Methods.

medium. To detect membrane CEA, membrane fraction of cell homogenate was used [22]. Quantitative analysis of CEA expression on each cell membrane was impossible by these methods. Flow cytometric analysis, however, has an advantage in feasibility, sensitivity and reproducibility for the assay of CEA expression. Valet et al. first used flow cytometry to demonstrate the CEA expression of solid tumor cells taken from patients [28]. However, only a few investigations have determined CEA in single-cell suspensions from solid tumors due to difficulties in tissue disintegration and preservation of antigenic determinants on cell surface $[8,26]$.

In the present study, we employed flow cytometric assay for GAC-T cells, which are maintained in a singlecell suspension culture. These cells produce small but distinct amounts of CEA in their cytoplasm after a long period from the primary culture [10]. This experimental system employing flow cytometrical assay and GAC-T cells enabled us to analyze the factors affecting CEA production, release, and cell surface expression in parallel experiments.

It is now well recognized that the synergistic inter-

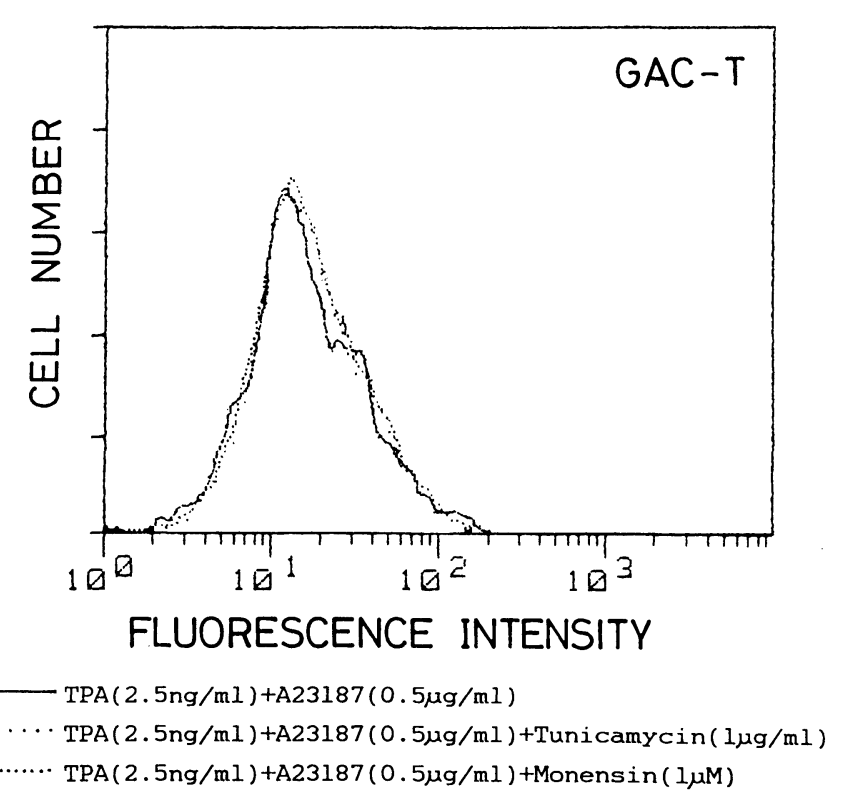

Fig. 8. The effects of tunicamycin and monensin on cell surface expression of CEA induced by A23187/TPA in GAC-T cells. The cells were cultured with the mixture of reagents at indicated concentrations for three days and subjected to flow cytometry, as described in Materials and Methods.

action between the tumor-promoting phorbol esters, such as TPA, and calcium ionophore induce various biologic processes, including cell growth and differentiation [16]. TPA alone appears to demonstrate a positive action that initially activates PKC followed by various cellular responses [17]. Our present study showed that TPA and A23187 could increase both cytoplasmic and cell surface expression of CEA on gastric cancer cells in a synergistic manner. The cell surface expression of CEA in GAC-T cells was revealed $24 \mathrm{hr}$ after stimulation with TPA/A23187. This observation suggested that de novo CEA was synthesized and transported into the cell surface.

Increasing intensity of CEA-specific immunofluorescence and immunoblot bands may support this idea. As shown by Western blot analysis, main CEA molecules in the lysates of GAC-T cells treated by TPA/A23187 consisted of two distinct molecular weights, approximately 170,000 and 140,000 . The band of 140,000 may be consistent with an immature form of CEA, which was detected by pulse chase study with $\left[{ }^{14} \mathrm{C}\right]$ leucine and $\left[{ }^{3} \mathrm{H}\right]$ mannose [11]. In our study, increases of immature and mature CEA were detected in GAC-T cells when stimulated by TPA/A23187. On the other hand, GAC-T cells stimulated with TPA alone showed a single broad band of mature form CEA. This finding indicated that TPA stimulated CEA production and its maturation by glycosylation in GAC-T cells. However, A23187 alone inhibited the maturation of CEA molecules in GAC-T cells (Fig. 2A-lane b, d). Recently, calcium ionophore was reported to perturb the transport of newly synthesized 
proteins of endoplasmic reticulum to the Golgi apparatus [4]. Our observations coincide with the report. These results have suggested that the cell surface CEA was induced by different processings or was under different regulatory systems.

Monensin is an ionophore that blocks protein transport at the trans-Golgi side and results in the retention of some proteins in the Golgi apparatus [9, 27]. Tunicamycin is an antibiotic that specifically blocks the synthesis of $\mathrm{N}$-acetylglucosamine-lipid intermediates, thereby preventing glycosylation of glycoproteins [25, 29]. In the flow cytometric analysis, the addition of either tunicamycin or monensin produced no reduction of cell surface expression of CEA (mature or immature form) in GAC-T cells. On the other hand, monensin and tunicamycin decreased the amount of mature CEA molecules in both TPA/A23187-treated and untreated GAC-T cells when examined by Western blot analysis. When added in the culture, both agents inhibited cell proliferation of GAC-T cells.

Treatment with monensin increased smaller molecular size CEA in GAC-T cells. Mottola-Hartshorn et al. also found that monensin blocked broadening of the higher molecular band, producing a sharp 141,000 peak in human gastric cancer cells [15]. Miura and Kim found that tunicamycin treatment inhibited total cellular glycoprotein synthesis but did not affect CEA levels of cellular homogenate, membrane or cytosol fractions in the human colon cancer cell line [14]. The authors observed that full maturation with the carbohydrate portion of the CEA molecule is not essential for sorting into the membrane, and probably in secretion, in vitro. In the present study, stable cell surface localization of CEA was demonstrated in gastric cancer cells, even though they were perturbed metabolically with various drugs, such as calcium ionophore, and others. It is likely that stable expression of CEA on the cell surface may occur apart from synthesis and maturation of CEA molecules.

It has long been thought that CEA is not an absolute tumor marker of the gastrointestinal tract [23]. Immunohistochemical studies revealed that CEA is expressed to a certain extent on normal mucosa cells [1]. Recently, detection of CEA and its superfamily related mRNA were reported in normal colon mucosa and in colon carcinoma tissues [12, 21]. Molecular analysis has revealed that CEA belongs to the immunoglobulin superfamily and is attached to cell membranes by a GPI-anchor [24]. It was proposed that CEA functions as an intercellular adhesion molecule [3, 20, 32]. CEA may act in part in some intercellular recognition or receptor molecule as members of the immunoglobulin superfamily do. As for receptor molecules, GPI-anchored surface molecules were released from the cell surface by enzymatic cleavage and made soluble CEA in the plasma [24]. Ellison et al. found that, with exposure to a toxic condition, a large amount of CEA was released immediately in a bronchial carcinoma cell line [6]. Chakurabarty et al. also found that transforming growth factor- $\beta$ induced CEA secretion in a dose-dependent manner in human colon carcinoma MOSER cells [5]. In the present study, GAC-T cells stimulated with TPA produced increased amounts of mature-type CEA, both in the cell lysate and in the culture medium.

Internalization of antibody bound Thy-1, one of the GPI anchored proteins on $\mathrm{T}$ cells, has been documented [2]. Recently, we have also found that cell membrane CEA molecules on a human gastric cancer cell line are internalized by treatment with anti-CEA rabbit antibodies and that CEA molecules are localized in the invagination of the plasma membrane, vesicles, tubulous structures and multivesicular body (MVB), as detected by immunoelectron microscopy [18]. MVB is recognized as a cellular component involved in endocytotic pathways [30]. This finding may suggest the possibility of cell surface-bound CEA molecules as intracytoplasmic traffic. It may be that the recycling of CEA molecules between the cell surface and intracytoplasmic apparatus plays a role in maintaining the cell surface expression of CEA.

It was also reported that murine CEA molecules served as virus receptors for cellular recognition of them [31]. In humans, we know neither the fate of CEA released into the extracellular and luminal space of gastrointestinal tracts nor the physiological and pathological ligands to CEA. Further studies will be necessary to elucidate the physiological functions of CEA.

\section{Acknowledgments}

The authors would like to thank Ms. M. A. Gere for editorial assistance.

\section{References}

1. Ahnen, D. J., Nakane, P. K. and Brown, W. P.: Ultrastructural localization of carcinoembryonic antigen in normal intestine and colon cancer. Abnormal distribution of CEA on the surfaces of colon cancer cells. Cancer 49; 2077-2090, 1982.

2. Bamezai, A., Goldmacher, V., Reiser, H. and Rock, K. L.: Internalization of phosphatidylinositol-anchored lymphocyte proteins. I. Documentation and potential significance for T cell stimulation. J. Immunol. 143; 3107-3116, 1989.

3. Benchimol, S., Fuks, A., Jothy, S., Beauchemin, N., Shirota, K. and Stanners, C. P.: Carcinoembryonic antigen, a human tumor marker, functions as an intercellular adhesion molecule. Cell 57; 327-334, 1989.

4. Booth, C. and Koch, G. L. E.: Perturbation of cellular calcium induces secretion of luminal ER proteins. Cell 59; 729-737, 1989.

5. Chakurabarty, S., Tobon, A., Varani, J. and Brattain, M. G.: Induction of carcinoembryonic antigen secretion and modulation of protein secretion/expression and fibronectin/laminin expression in human colon carcinoma cells by transforming growth factor- $\beta$. Cancer Res. 48; 4059-4064, 1988.

6. Ellison, M. L., Lamb, D., Rivett, J. and Neville, A. M.: Quantitative aspects of carcinoembryonic antigen output by a human lung carcinoma cell line. J. Natl. Cancer Inst. 59; 309-312, 1977.

7. Gold, P. and Freedman, S. O.: Demonstration of tumor- 
specific antigens in human colonic carcinomata by immunological tolerance and absorption techniques. J. Exp. Med. 121; 439-462, 1965.

8. Hareyama, M., Imai, K., Kubo, K., Takahashi, H., Koshiba, H., Hinoda, Y., Shidou, M., Oouchi, A., Yachi, A. and Morita, K.: Effect of radiation on the expression of carcinoembryonic antigen of human gastric adenocarcinoma cells. Cancer 67; 2269-2274, 1991.

9. Kääriäinen, L., Hashimoto, K., Saraste, J., Virtanen, I. and Penttinen, K.: Monensin and FCCP inhibit the intracellular transport of alphavirus membrane glycoproteins. J. Cell Biol. 87; 783-791, 1980.

10. Kanazawa, S., Morikawa, S., Harada, T., Yasuhira, K., Matsubara, Y., Ikeda, S., Soeda, S. and Fujimura, M.: Carcinoembryonic antigen producing cultured cell lines enable detection of autoantibodies in sera from patients with gastrointestinal cancer. Cancer 50; 1775-1782, 1980.

11. Kuroki, M., Kuroki, M., Ichiki, S. and Matsuoka, Y.: Identification and partial characterization of the unglycosylated peptide of carcinoembryonic antigen synthesized by human tumor cell lines in the presence of tunicamycin. Mol. Immunol. 21; 743-746, 1984.

12. Kuroki, M., Arakawa, F., Yamamoto, H., Shimura, H., Ikehara, Y. and Matsuoka, Y.: Active production and membrane anchoring of carcinoembryonic antigen observed in normal colon mucosa. Cancer Lett. 43; 151-157, 1988.

13. Lowry, O. H., Rosebrough, N. J., Farr, A. L. and Randall, R. J.: Protein measurement with the folin phenol reagent. $J$. Biol. Chem. 193; 265-275, 1951.

14. Miura, S. and Kim, Y.S.: Effect of tunicamycin on synthesis and secretion of carcinoembryonic antigen by human colonic adenocarcinoma cells. Int. J. Cancer 38; 197-205, 1986.

15. Mottola-Hartshorn, C., Lorenzoni, P. and Ceccarini, C.: Biosynthesis and glycosylation of the carcinoembryonic antigen. Biochem. J. 255; 943-948, 1988.

16. Nishizuka, Y.: The role of protein kinase $C$ in cell surface signal transduction and tumor promotion. Nature 308; 693697, 1984.

17. Nishizuka, Y.: The molecular heterogeneity of protein kinase $\mathrm{C}$ and its implications for cellular regulation. Nature 334; 661$665,1988$.

18. Ohiwa, K., Harada, T., Morikawa, S. and Nakamura, T.: Immunoelectron microscopic localization of carcinoembryonic antigen in gastric adenocarcinoma cell lines. Pathol. Intern. (formerly Acta Path. Jpn.) 44; 635-644, 1994.

19. Oikawa, S., Nakazato, H. and Kosaki, G.: Primary structure of human carcinoembryonic antigen (CEA) deduced from cDNA sequence. Biochem. Biophys. Res. Commun. 142; 511$518,1987$.
20. Pignatelli, M., Durbim, H. and Bodmer, W. F.: Carcinoembryonic antigen functions as an accessory adhesion molecule mediating colon epithelial cell-collagen interactions. Proc. Natl. Acad. Sci. USA 87; 1541-1545, 1990.

21. Sato, C., Miyaki, M., Oikawa, S., Nakazato, H. and Kosaki, G.: Differential expression of carcinoembryonic antigen and nonspecific crossreacting antigen genes in human colon adenocarcinomas and normal colon mucosa. Jpn. J. Cancer Res. (Gann) 79; 433-437, 1988.

22. Shi, Z. R., Tsao, D. and Kim, Y. S.: Subcellular distribution, synthesis, and release of carcinoembryonic antigen in cultured human colon adenocarcinoma cell lines. Cancer Res. 43; 40454049, 1983.

23. Stockley, R. A., Shaw, J., Whitfield, A. G. W. Whitehead, T. P., Clarke, C. A. and Burnett, D.: Effect of cigarette smoking, pulmonary inflammation, and lung disease on concentration of carcinoembryonic antigen in serum and secretions. Thorax 41; 17-24, 1986.

24. Takami, N., Misumi, Y., Kuroki, M., Matsuoka, Y. and Ikehara, Y.: Evidence for carboxyl-terminal processing and glycolipid-anchoring of human carcinoembryonic antigen. $J$. Biol. Chem. 263; 12716-12720, 1988.

25. Takatsuki, A., Arima, K. and Tamura, G.: Tunicamycin, a new antibiotic. I. Isolation and characterization of tunicamycin. J. Antibiotics 24; 215-223, 1971.

26. Tamai, M., Tanimura, H., Yamaue, H., Iwahashi, M., Tsunoda, T., Tani, M., Noguchi, H., Hotta, T. and Arii, K.: Expression of carcinoembryonic antigen in fresh human gastric cancer cells assessed by flow cytometry. J. Surg. Oncol. 52; 176-180, 1993.

27. Tartakoff, A.M. and Vassalli, P.: Plasma cell immunoglobulin secretion. Arrest is accompanied by alteration of Golgi complex. J. Exp. Med. 146; 1332-1345, 1977.

28. Valet, G., Rüssmann, L. and Wirsching, R.: Automated flowcytometric identification of colo-rectal tumor cells by simultaneous DNA, CEA-antibody and cell volume measurements. J. Clin. Chem. Clin. Biochem. 22; 935-942, 1984.

29. von Figura, K., Rey, M., Prinz, R., Voss, B. and Ullrich, K.: Effect of tunicamycin on transport of lysosomal enzymes in cultured skin fibroblasts. Eur. J. Biochem. 101; 103-109, 1979.

30. Warren, G.: Trawling for receptors. Nature 346; 318-319, 1990.

31. Yokomori, K. and Lai, M. M.: Mouse hepatitis virus utilizes two carcinoembryonic antigens as alternative receptors. $J$. Virol. 66; 6194-6199, 1992.

32. Zhou, H., Fuks, A., Alcaraz, G., Bolling, T. J. and Stanners, C. P.: Homophilic adhesion between Ig superfamily carcinoembryonic antigen molecules involves double reciprocal bonds. $J$. Cell Biol. 122; 951-960, 1993. 